Article

\title{
Synthesis of Fucosyl-Oligosaccharides Using $\alpha$-L-Fucosidase from Lactobacillus rhamnosus GG
}

\author{
Yolanda Escamilla-Lozano ${ }^{1}$, Francisco Guzmán-Rodríguez ${ }^{1}$, Sergio Alatorre-Santamaría ${ }^{1}$, \\ Mariano García-Garibay ${ }^{1,2}$, Lorena Gómez-Ruiz ${ }^{1}$, Gabriela Rodríguez-Serrano ${ }^{1}$ and \\ Alma Cruz-Guerrero ${ }^{1, *}$
}

1 Departamento de Biotecnología, Universidad Autónoma Metropolitana-Iztapalapa, Cd. de México 09340, Mexico

2 Departamento de Ciencias de la Alimentación, Universidad Autónoma Metropolitana-Lerma, Edo. México 52006, Mexico

* Correspondence: aec@xanum.uam.mx; Tel.: +52-558-044-720

Academic Editor: Derek J. McPhee

Received: 31 May 2019; Accepted: 28 June 2019; Published: 29 June 2019

\begin{abstract}
Fucosyl-oligosaccharides are natural prebiotics that promote the growth of probiotics in human gut and stimulate the innate immune system. In this work, the release of $\alpha$-L-fucosidase by Lactobacillus rhamnosus GG, and the use of this enzyme for the synthesis of fucosyl-oligosaccharides were investigated. Since $\alpha$-L-fucosidase is a membrane-bound enzyme, its release from the cells was induced by addition of 4-nitrophenyl- $\alpha$-L-fucopyranoside ( $p$ NP-Fuc). Enzyme activity associated with the cell was recovered at $78 \%$ of its total activity. Fucosyl-oligosaccharides where synthesized using $\alpha$-L-fucosidase extract and $p$ NP-Fuc as donor substrate, and D-lactose or D-lactulose as acceptor substrates, reaching a yield up to $25 \%$. Fucosyllactose was obtained as a reaction product with D-lactose, and its composition was confirmed by mass spectrometry (MALDI-TOF MS). It is possible that the fucosyl-oligosaccharide synthesized in this study has biological functions similar to human milk oligosaccharides.
\end{abstract}

Keywords: fucosidase; fucosyl-oligosaccharides; Lactobacillus rhamnosus GG; transfucosylation

\section{Introduction}

Fucosyl-oligosaccharides are present on cell surfaces and in blood group antigens, intestinal mucin, and human milk. Their anti-adhesive activity toward infective microorganisms has been reported, thereby preventing adhesion of pathogens to infant mucosal surfaces and decreasing the risk for bacterial infections and diarrhea [1]. Furthermore, the most abundant human milk oligosaccharides (HMOs) are fucosyl-oligosaccharides, proven to inhibit adhesion of pathogenic microorganisms such as Campylobacter jejuni, Vibrio cholerae, Salmonella, and Shigella. These oligosaccharides are natural prebiotics and stimulate the innate immune system [2-4]. Therefore, the synthesis of fucosyl-oligosaccharides has currently been receiving great attention, due to their important roles in the many biological processes described above.

There is great interest in enzymatic HMO synthesis, not only due to the fact that chemical synthesis involving saccharides is a cumbersome task, usually relying on multiple steps, complicated protective group manipulations, and the use of potentially toxic reagents [5]. Several examples of glycosidases applied in the synthesis of oligosaccharides have been reported in the literature [6,7]. Particularly, $\alpha$-L-fucosidases can be employed for the production of valuable compounds by transfucosylation reactions, which are crucial intermediates in the synthesis of HMOs.

$\alpha$-L-Fucosidases play an important role in the metabolism of biological substrates containing L-fucose. These enzymes have been isolated from prokaryotic and eukaryotic cells and are classified 
into four groups: those from microorganisms [8,9], marine mollusks [10], plants [11], and mammals [12]. Their substrate specificity differs depending on their origin.

There are few reports of $\alpha$-L-fucosidases from Lactobacillus, a genus that includes several probiotic bacteria which are common in the human intestine [13,14]. A study of the genomic analysis of 25 Lactobacillus species reveals that Lactobacillus rhamnosus encodes putative $\alpha$-L-fucosidases [15]. In particular, Escamilla-Lozano et al. [13] reported the synthesis of cell-associated $\alpha$-L-fucosidases by Lactobacillus rhamnosus GG employing different carbon sources. Rodríguez-Díaz et al. [16] employed the recombinant fucosidases AlfB and AlfC from Lactobacillus casei BL23 to synthesize fucosyl- $\alpha-(1-3)-N$-acetyl-D-glucosamine and fucosyl- $\alpha-(1-6)-N$-acetyl-D-glucosamine, respectively. Therefore, the aim of this work was to study the release of $\alpha$-L-fucosidase from Lactobacillus rhamnosus GG, and the use of this enzyme for the synthesis of fucosyl-oligosaccharides with composition similarity to those found in human milk.

\section{Results and Discussion}

\section{1. $\alpha$-L-Fucosidase Release}

Figure 1 shows the $\alpha$-L-fucosidase released from cultured cells when exposed to 4-nitrophenyl- $\alpha$-L-fucopyranoside (pNP-Fuc), recovering $78 \%$ of its total activity. The obtained supernatant containing enzyme extract was set aside and stored for further use in the synthesis of fucosyl-oligosaccharides. Interestingly, the release of $\alpha$-L-fucosidase promoted by $p$ NP-Fuc suggests that this compound should be playing an important role in the enzyme excretion by the cells. Sikkema et al. [17] indicated that apolar compounds, such as nitrophenol, could easily penetrate the lipid bilayer of the cytoplasmic membrane, potentially causing significant changes in its structure and integrity. Furthermore, accumulation of apolar compounds in the membrane can lead to modification of membrane fluidity which may manifest by swelling of the lipid bilayer. Additionally, the lipid annulus which surrounds membrane-embedded proteins would also be affected causing altered protein conformations. This could explain why membrane-bound $\alpha$-L-fucosidase was released into the medium when the microorganism was in the presence of $p$ NP-Fuc. Moreover, it was observed that activity of $\alpha$-L-fucosidase was conserved in cell membrane debris (data not shown). This data would indicate that the L. rhamnosus GG $\alpha$-L-fucosidase is a membrane-bound enzyme, similar to what is observed for $\alpha$-L-fucosidase from Bifidobacterium bifidum [18]. Dong et al. [19] reported that after chromatographic steps, $27 \%$ of the intracellular $\alpha$-L-fucosidase from Wenyingzhuangia fucanilytica was recovered, while Eneyskaya et al. [20] obtained a yield of 30\% of the initial activity of the intracellular $\alpha$-L-fucosidase from Thermus sp.

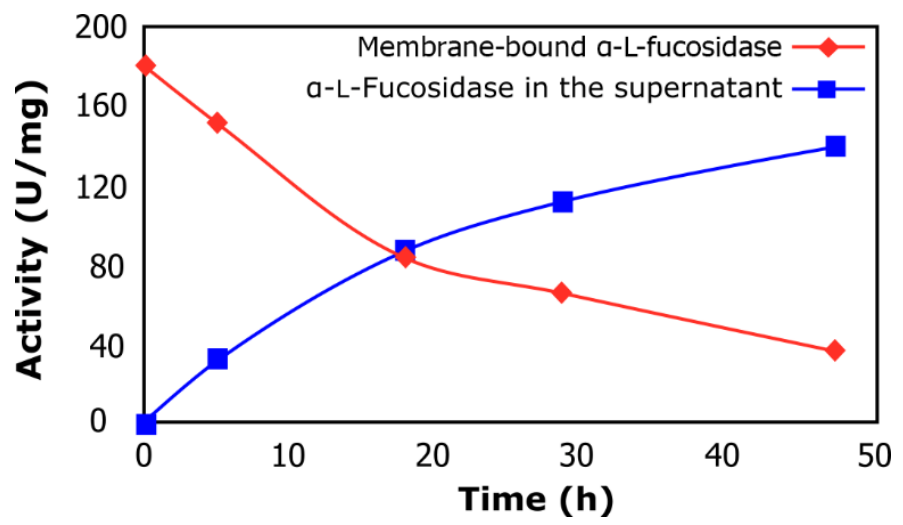

Figure 1. $\alpha$-L-Fucosidase release from cells of L. rhamnosus GG. Membrane-bound $\alpha$-L-fucosidase (rhombus); $\alpha$-L-fucosidase in the supernatant (squares). 


\subsection{Synthesis of Fucosyl-Oligosaccharides}

Figure 2a shows a typical chromatogram of the products obtained during the transfucosylation reaction. The retention time registered for the synthesized fucosyl-oligosaccharide (15.7 $\mathrm{min})$ was similar to that of $2^{\prime}$-fucosyllactose (15.6 min) (Figure $2 b$ ). As can be noted in Figure 2a, during the course of the enzymatic reaction, $\alpha$-L-fucosidase performed the hydrolysis of $p$ NP-Fuc as well as transfucosylation, resulting in the production of fucosyl-oligosaccharide.

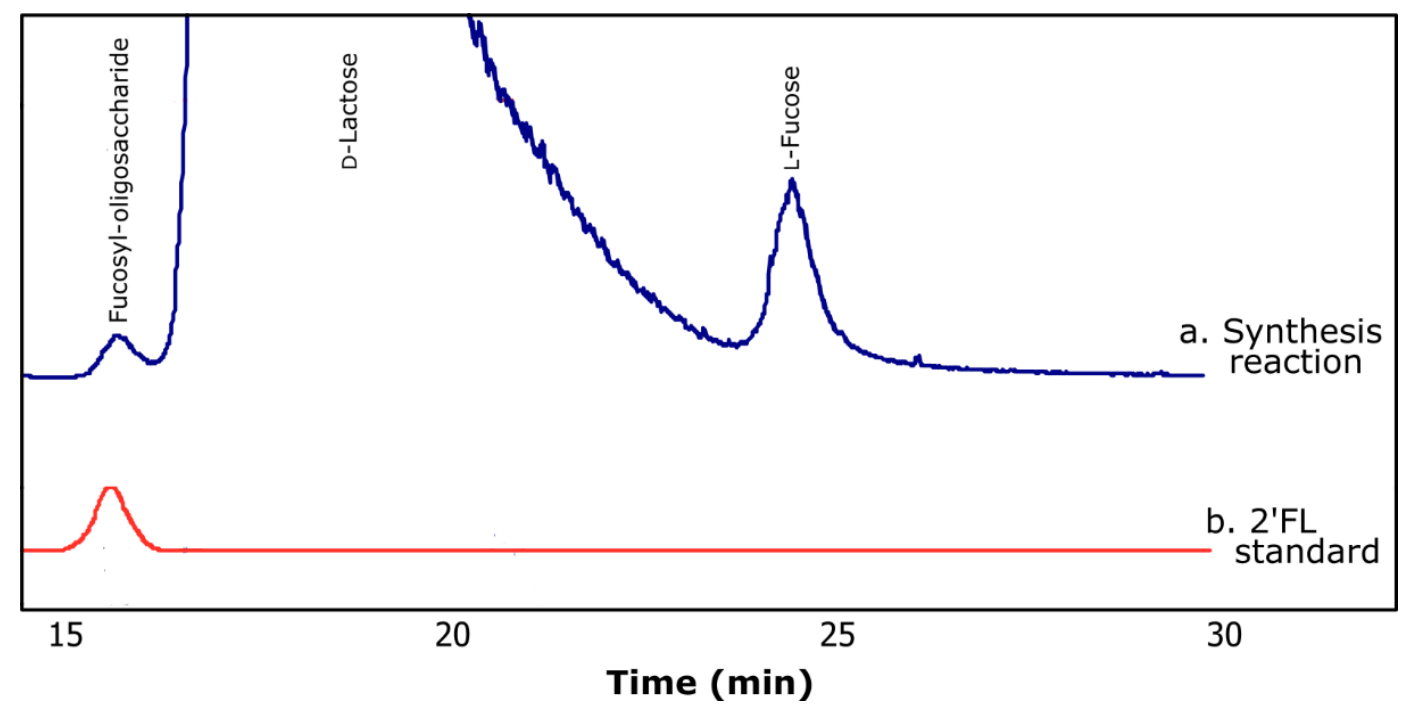

Figure 2. Typical chromatograms obtained by HPLC using ELSD for (a) transfucosylation reaction and (b) 2'-fucosyllactose standard (2'FL).

Figure 3 shows the reaction course of a typical transfucosylation reaction when using D-lactose or D-lactulose as acceptor substrate. The final concentration of fucosyl-oligosaccharides synthesized after $12 \mathrm{~h}$ reaction was $1.16 \mu \mathrm{mol} / \mathrm{mL}$ for D-lactose and $0.87 \mu \mathrm{mol} / \mathrm{mL}$ for D-lactulose. The ability to synthesize fucosyl-oligosaccharides employing $\alpha$-L-fucosidase from L. rhamnosus GG is reported here for the first time, opening a wide field of investigation into the transfucosylation reaction to obtain HMO mimics.

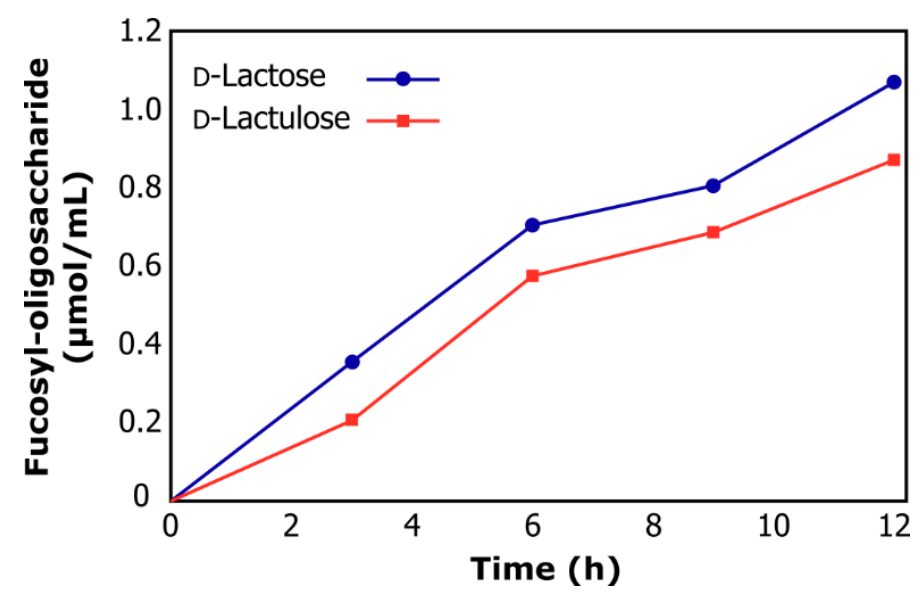

Figure 3. Reaction course of transfucosylation catalyzed by $\alpha$-L-fucosidase from L. rhamnosus GG using D-lactose (circles) and D-lactulose (squares) as acceptor substrates.

The enzymatic synthesis of fucosyl-oligosaccharides offers the advantage of forming specific glycosidic linkages in the presence of other reactive functional groups. Furthermore, transfucosylation 
reactions demand an activated donor substrate, which means that the fucose moiety that is to be transferred must form a high energy bond with a good leaving group, so that the energy provided by cleaving this bond contributes to lowering the activation energy in the transglycosylation reaction, and the most reported substrate in transfucosylation reactions is $p$ NP-Fuc $[7,21,22]$. The transglycosylation activity of $\alpha$-L-fucosidases is generally moderate compared with the hydrolysis activity, although it is variable and depends on the origin of the enzyme. Rodriguez-Diaz et al. [16] reported that $\alpha$-L-fucosidases AlfB and AlfC from L. casei BL23 can able to synthesize by transglycosylation the disaccharides fucosyl- $\alpha-(1-3)-N$-acetylglucosamine and fucosyl- $\alpha-(1-6)-N$-acetylglucosamine, respectively. Zeng et al. [23] studied the regioselectivity of $\alpha$-L-fucosidase from Alcaligenes sp. to fucosylate $p$-nitrophenyl glycosides ( $p$ NP-lactosamine, $p$ NP-lactose) using $p$ NP-Fuc as the donor. In both cases, fucosylation occurred preferably on carbon 3 of galactose. Zeuner et al. [7] studied the ability of the BbAfcB fucosidase from B. bifidum JCM 1254 to transfer fucose from 3-fucosyllactose to lacto- $N$-tetraose for the synthesis of lacto- $N$-fucopentaose II, and reported that this fucosidase is regioselective toward both hydrolysis and the formation of $\alpha-1,3 / 4$ fucosidic bonds. We are currently studying the regioselectivity of the $\alpha$-L-fucosidase of L. rhamnosus GG to reveal which isomers of the fucooligosaccharides can be obtained during the transfucosylation reaction.

As summarized in Table 1, transfucosylation using D-lactose or D-lactulose as acceptor substrate afforded the desired oligosaccharides at $21 \%$ and $25 \%$ yield, respectively. The yields are comparable with those reported previously by Ajisaka and Shirakabe [24] for fucosidase from Corynebacterium sp. when methyl- $\beta$-D-galactopyranoside (25\%) and D-galactose (18\%) were used as acceptor substrates. Likewise, Farkas et al. [25] reported yields of $25 \%$ to $29 \%$ using fucosidase from Penicillium multicolor with different acceptor substrates. Rodríguez-Díaz et al. [16] reported that $\alpha$-L-fucosidase AlfB from $L$. casei BL23 was able to synthesize fucosyl- $\alpha-(1-3)-N$-acetylglucosamine with a yield of $23 \%$, while the $\alpha$-L-fucosidase AlfC synthesized fucosyl- $\alpha-(1-6)-N$-acetyl-D-glucosamine with a yield of $56 \%$. Guzmán-Rodríguez et al. [26] employed $\alpha$-L-fucosidase from Thermotoga maritima for the synthesis of fucosyllactose with a of yield 32.5\%. Furthermore, Zeuner et al. [6] and Petschacher and Nidetzky [27] reported that typically, wild-type fucosidases can reach a $30-40 \%$ yield in transfucosylation reactions.

Table 1. Synthesis of fucosyl-oligosaccharide using $\alpha$-L-fucosidase released from L. rhamnosus GG.

\begin{tabular}{ccc}
\hline Acceptor Substrate & Oligosaccharide $(\mu \mathrm{mol} / \mathbf{m L})$ & Yield * $\mathbf{\%})$ \\
\hline D-Lactose & 0.75 & 21 \\
D-Lactulose & 1.16 & 25 \\
D-Galactose & 0 & 0 \\
\hline
\end{tabular}

* Yield was calculated based on the donor substrate.

On the other hand, when D-galactose was used as acceptor substrate, no transfer (Table 1) or hydrolysis reaction were observed, which was verified by the fact that 4-nitrophenol $(p N P)$ was absent in the reaction media. Reglero and Cabezas [28], and Grove and Serif [29] reported the D-galactose-induced inhibition of fucosidases from boar and mollusk, giving rise to the hypothesis that $\alpha$-L-fucosidase from $L$. rhamnosus GG could also exhibit inhibitory effects.

\subsection{Composition of Synthesized Fucosyl-Oligosaccharide}

To prove that the synthesized compound was fucosyllactose, when using D-lactose as acceptor substrate, the synthesized compound was purified and subjected to acid hydrolysis. Figure 4a shows a chromatogram of the purified fucosyl-oligosaccharide. Using HPLC, the moieties released in equimolar concentration from acid-hydrolyzed compound were identified as D-glucose, D-galactose, and L-fucose, as shown in Figure $4 b$, supporting the formation of the fucosyl-oligosaccharide. 


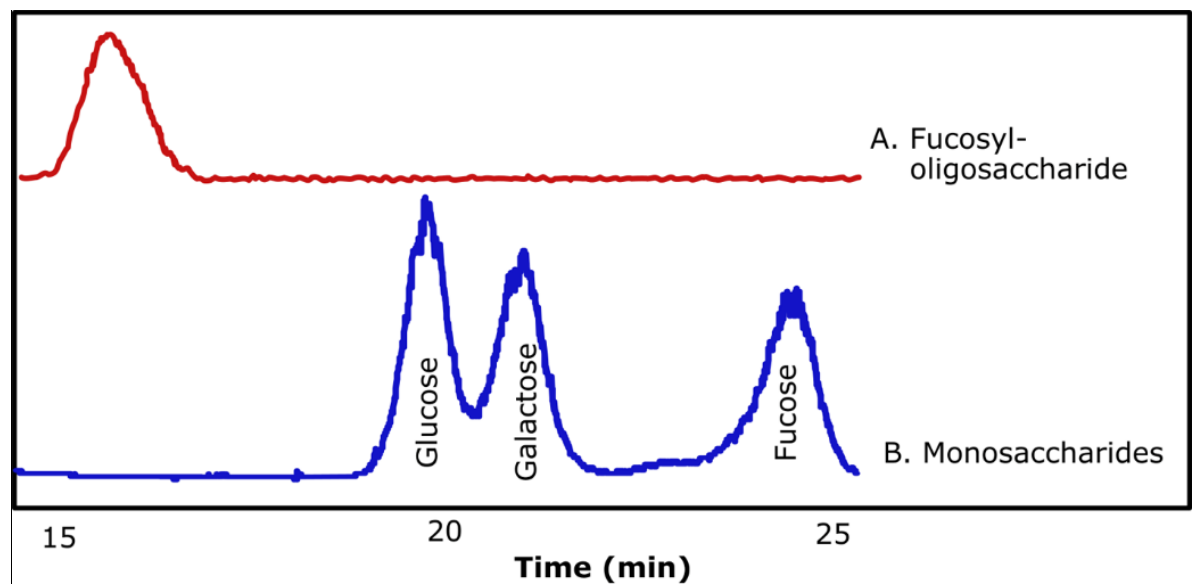

Figure 4. Chromatograms obtained by HPLC using ELSD of purified fucosyl-oligosaccharide (A) and monosaccharides obtained after acid hydrolysis of purified fucosyl-oligosaccharide (B).

Purified fucosyl-oligosaccharide was subjected to MALDI-TOF MS analysis. In the mass spectrum of the compound (Figure 5a), the strongest signal $(\mathrm{m} / \mathrm{z}$ 511.008) corresponds to the mass of a fucosyllactose- $\mathrm{Na}^{+}$adduct. Subsequent fragmentation of the molecular ion (Figure 5b) reveals the presence of three hexoses, where one is a fucose moiety. Data from the MS/MS spectrum in conjunction with acid hydrolysis/HPLC confirms that the synthetized oligosaccharide corresponds to fucosyllactose. Guzmán-Rodríguez et al. [26] employed MALDI-TOF MS to identify a fucosyllactose produced via transglycosylation by $\alpha$-L-fucosidase from Thermotoga maritima. They found a fucose and two hexoses in the structure of the produced fucosyl-oligosaccharide. It has been reported that human milk fucosyl-oligosaccharides have shown an anti-infectious effect against several pathogens. Ruiz Palacios et al. [30] found that $\alpha-1,2$-fucosyl-oligosaccharides inhibited the adhesion of Campylobacter jejuni to HEp-2 cell line. Weichert et al [31] reported that 2'-fucosyllactose inhibited the adhesion of Salmonella enterica serovar fyris to Caco- 2 cell line. This last group also reported that $2^{\prime}$-fucosyllactose, as well as its isomer 3-fucosyllactose, inhibit the adhesion of enteropathogenic Escherichia coli and Pseudomonas aeruginosa to different human cell lines, showing that at least two isomers of the same fucosyl-oligosaccharide can express a similar bioactivity. In addition, Sotgiu et al. [32] reported that 2'-fucosyllactose has a positive effect on the immune system, since it increases the production of the anti-inflammatory cytokine IL-10, and decreases the levels of the proinflammatory IL-12 in mononuclear cells. Duska-McEwen et al. [33] reported that 2'-fucosyllactose and 3-fucosyllactose can structurally mimic histo-blood group antigens and block the binding of norovirus, which can cause acute gastroenteritis in humans. 

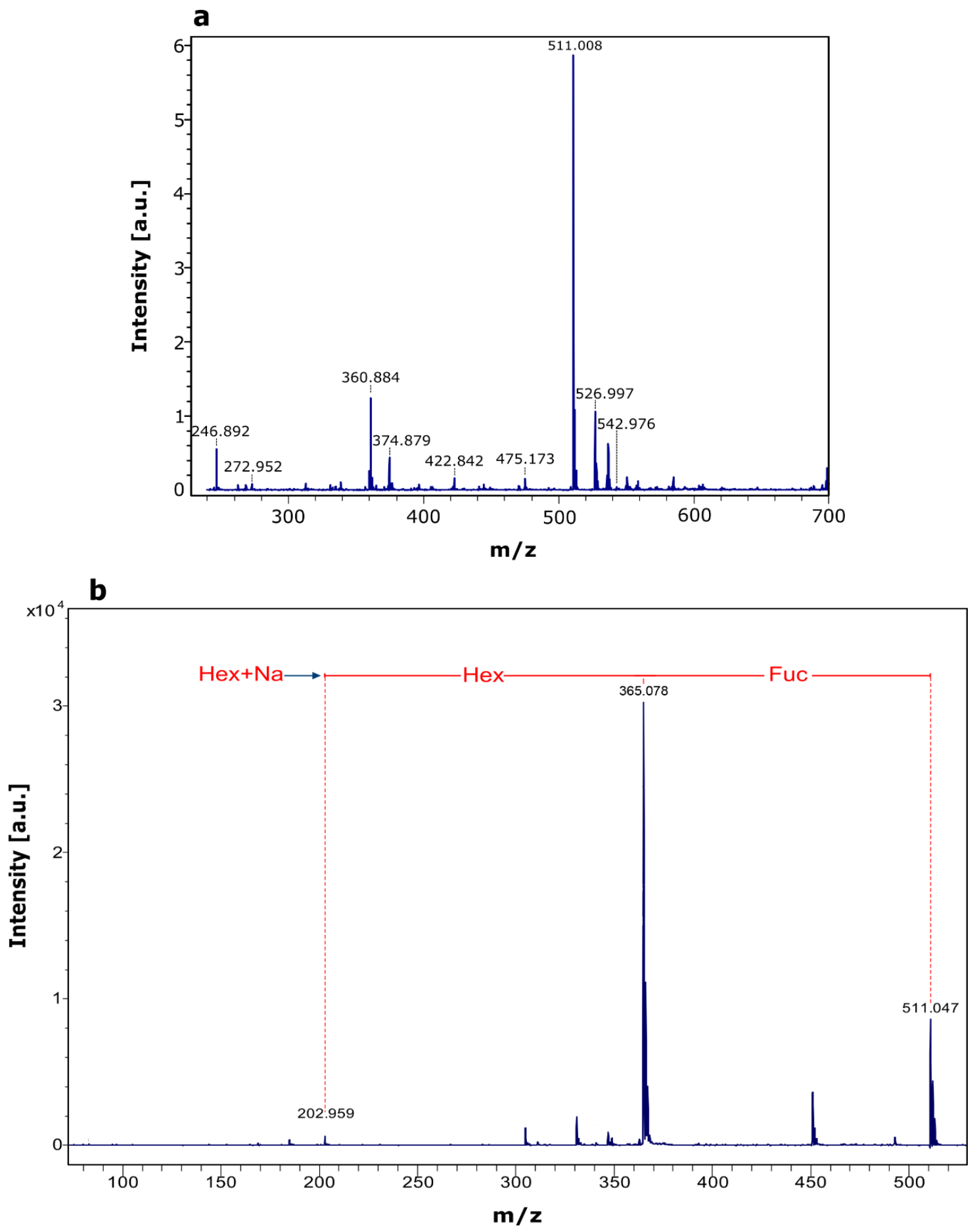

Figure 5. MALDI-TOF MS analysis of purified fucosyl-oligosaccharide. (a) MS spectrum of purified compound, (b) MS/MS spectrum of precursor ion ( $m / z$ 511.008).

\section{Materials and Methods}

\subsection{Materials}

Yeast extract and casein peptone were purchased from B. D. Bioxon (Mexico City, Mexico). $p$ NP-Fuc, $p$ NP, D-lactose, D-glucose, D-galactose, L-fucose, and Man Rogosa and Sharpe (MRS) agar were purchased from Sigma-Aldrich (St. Louis, MO, USA), 2'-fucosyllactose was purchased from 
Carbosynth (Berkshire, UK). Sodium phosphate and sodium hydroxide were purchased from J. T. Baker (Mexico City, Mexico). Milli-Q®(Billerica, MA, USA) water was used throughout the experiments.

\subsection{Microorganism}

Lactobacillus rhamnosus GG, previously isolated by Cruz-Guerrero et al. [34], was used in this study. The culture was stored in MRS agar at $4{ }^{\circ} \mathrm{C}$.

\subsection{Production of $\alpha$-L-Fucosidase}

Production of $\alpha$-L-fucosidase was performed as previously described by Escamilla-Lozano et al. [13]. In brief, L. rhamnosus GG was cultivated in a culture medium at $37^{\circ} \mathrm{C}$ for $24 \mathrm{~h}$. The culture medium contained $5 \mathrm{~g} / \mathrm{L}$ yeast extract, $10 \mathrm{~g} / \mathrm{L}$ casein peptone, and $10 \mathrm{~g} / \mathrm{L}$ D-glucose. Fermentation broth was centrifuged at 3110× $g$ (Beckman J2-MI, Beckman Instruments, Palo Alto, CA, USA) for $20 \mathrm{~min}$ at $4{ }^{\circ} \mathrm{C}$. Cellular pellet was resuspended in phosphate buffer $(100 \mathrm{mM}, \mathrm{pH} 7)$, to analyze for $\alpha$-L-fucosidase activity.

\subsection{Release of $\alpha$-L-Fucosidase}

Cell pellets, obtained as described above, were washed twice with isotonic solution ( $\mathrm{NaCl} 0.9 \%)$. The cells were added to a solution containing $0.5 \mathrm{~g} / \mathrm{L}$ of $p N P$-Fuc and incubated at $37^{\circ} \mathrm{C}$ for $48 \mathrm{~h}$. Samples were taken periodically and centrifuged at $3110 \times g$ for $20 \mathrm{~min}$ at $4{ }^{\circ} \mathrm{C}$. Both supernatant and cellular pellet were resuspended in phosphate buffer $(100 \mathrm{mM}, \mathrm{pH} 7)$ and analyzed for $\alpha$-L-fucosidase activity. Released enzyme in the supernatant was used for the synthesis of fucosyl-oligosaccharides.

\subsection{Enzyme Activity Assay}

Membrane-bound $\alpha$-L-fucosidase activity was determined by using $400 \mu \mathrm{L}$ of the resuspended cell pellet and $1600 \mu \mathrm{L}$ of $3.5 \mathrm{mM} p$ NP-Fuc in $100 \mathrm{mM}$ phosphate buffer (pH 7). The mixture was incubated for $2 \mathrm{~h}$ at $37^{\circ} \mathrm{C} ; 200 \mu \mathrm{L}$ aliquots of samples were removed every $30 \mathrm{~min}$ and centrifuged at $3110 \times g$ for $20 \mathrm{~min}$ at $4{ }^{\circ} \mathrm{C}$ to eliminate cells. The amount of $p$ NP released was quantified in a spectrophotometer (Shimadzu UV-160A, Tokyo, Japan) at $410 \mathrm{~nm}$. Activity from released $\alpha$-L-fucosidase was determined by using $200 \mu \mathrm{L}$ of the supernatant and $800 \mu \mathrm{L}$ of $3.5 \mathrm{mM} p$ NP-Fuc in $100 \mathrm{mM}$ phosphate buffer (pH 7). The mixture was incubated for $10 \mathrm{~min}$ at $37^{\circ} \mathrm{C}$, and the $p \mathrm{NP}$ released was recorded in a spectrophotometer at $410 \mathrm{~nm}$. The molar extinction coefficient $(\varepsilon)$ of the $p$ NP under the conditions described was $7.8 \mathrm{mM}^{-1} \mathrm{~cm}^{-1}$.

One unit of $\alpha$-L-fucosidase was defined as the amount of enzyme required to release $1 \mathrm{nmol}$ of $p \mathrm{NP}$ per minute at $\mathrm{pH} 7$ and $37^{\circ} \mathrm{C}$. Specific $\alpha$-L-fucosidase activity was defined as enzymatic activity (U) per mg of biomass, which was measured using a standard curve of dry weight cells.

\subsection{Synthesis of Fucosyl-Oligosaccharides}

The synthesis of fucosyl-oligosaccharides with $\alpha$-L-fucosidase from L. rhamnosus GG was performed using D-lactose, D-lactulose, and D-galactose as acceptor substrate at $200 \mathrm{mg} / \mathrm{mL}$, and $p \mathrm{NP}$-Fuc at $1 \mathrm{mg} / \mathrm{mL}$ as a donor substrate. The enzymatic transfucosylation reaction was accomplished in a stirred vessel in a total volume of $10 \mathrm{~mL}$. Acceptor and donor substrates were dissolved in $100 \mathrm{mM}$ phosphate buffer ( $\mathrm{pH}$ 7), and $3.8 \mathrm{U} / \mathrm{mL}$ of $\alpha$-L-fucosidase was added. The mixture was incubated at $37^{\circ} \mathrm{C}$ for $12 \mathrm{~h}$, and aliquots were taken at regular intervals. Reaction was stopped by heating at $100{ }^{\circ} \mathrm{C}$ for $5 \mathrm{~min}$. The carbohydrates of the mixture were analyzed as described below. Yields of transfucosylation were calculated based on donor substrate. The concentration of synthesized fucosyl-oligosaccharides was determined from the integration of area on HPLC chromatograms and the interpolation of peak area on a calibration curve of an external standard ( 2 -fucosyllactose). 


\subsection{Composition of Synthesized Fucosyl-Oligosaccharide}

Synthesized oligosaccharide was recovered by HPLC from a reaction using only lactose as an acceptor substrate. Collected samples were concentrated at $70{ }^{\circ} \mathrm{C}$, and the purity of the compound was verified by HPLC (See Section 3.8).

The purified fucosyl-oligosaccharide was also subjected to mass analysis according to Guzmán-Rodríguez et al. [21]. For this purpose, the compound was concentrated to $1 \mathrm{mg} / \mathrm{mL}$ and analyzed using a Bruker Autoflex Speed MALDI-TOF/TOF system with a $1000 \mathrm{~Hz}$ Smart beam II laser. 2,5-Dihydroxybenzoic acid (DHB) was used as a matrix $\left(5 \mathrm{mg} / 100 \mathrm{~mL}\right.$ in $\left.50 \% \mathrm{ACN} / \mathrm{H}_{2} \mathrm{O}\right)$, and $0.01 \mathrm{M} \mathrm{NaCl}$ was added as a cation dopant to increase signal sensitivity. The sample was spotted on a stainless-steel target plate, followed by the $\mathrm{NaCl}$ dopant and the matrix. The spot was dried in a vacuum prior to mass spectrometric analysis. MALDI-TOF MS via collision-induced dissociation (CID) was then performed to confirm the structure of the oligosaccharide. Tandem mass (MS/MS) spectrum was gained at $1 \mathrm{keV}$ collision energy with argon gas.

To identify the monosaccharide moieties present in the structure of the oligosaccharide, an acid hydrolysis of the purified fucosyl-oligosaccharide was performed by adding $2 \mathrm{M} \mathrm{HCl}$ and incubated at $90^{\circ} \mathrm{C}$ for $3 \mathrm{~h}$. The hydrolysate was analyzed by HPLC to identify released monosaccharides (see Section 3.8).

\subsection{Carbohydrate Quantification}

Carbohydrates were determined by HPLC (LabAlliance, State College, PA, USA) using a Rezex RHM $7.8 \mathrm{~mm} \times 300 \mathrm{~mm}$ column (Phenomenex, Torrance, CA, USA) for monosaccharides and an evaporative-light-scattering detector (ELSD) (Polymer Laboratories, Amherst, MA, USA). Samples were eluted with deionized water at a flow rate of $0.3 \mathrm{~mL} / \mathrm{min}$. Column temperature was maintained at $75^{\circ} \mathrm{C}$, and detector temperature was kept at $110^{\circ} \mathrm{C}$. A standard $2^{\prime}$-fucosyllactose curve was used to quantify the fucosyl-oligosaccharide. Concentrations of monosaccharides (D-glucose, D-galactose, and L-fucose) were calculated using standard curves for each one.

\section{Conclusions}

In this work, we report the release of $\alpha$-L-fucosidase from L. rhamnosus GG and its further application to synthesize fucosyllactose through transfucosylation reaction, which proved to be an alternative route for the production of fucosyl-oligosaccharide. Due to the fucosyl-oligosaccharide synthesized in this work having a composition similar to HMOs, they could provide the same advantages to human health as prebiotics and anti-infective compounds, which could of benefit to infants who are unable to be breastfed.

Author Contributions: Conceptualization, Y.E.-L. and A.C.-G.; Funding acquisition, A.C.-G.; Methodology, Y.E.-L., F.G.-R. and S.A.-S.; Project administration, A.C.-G.; Validation, M.G.-G., L.G.-R. and G.R.-S.; Writing-original draft, M.G.-G. and A.C.-G.; Writing-review \& editing, S.A.-S., L.G.-R. and A.C.-G.

Funding: This study was funded by National Council for Science and Technology of Mexico, grant number 180438. Conflicts of Interest: The authors declare no conflict of interest.

\section{References}

1. Miñana, I.V. Oligosacáridos en la leche humana. Acta Pediatr. Esp. 2007, 65, 175-179.

2. Bode, L. Human milk oligosaccharides: Every baby needs a sugar mama. Glycobiology 2009, 22, 1147-1162. [CrossRef] [PubMed]

3. Newburg, D.S. Neonatal protection by an innate immune system of human milk consisting of oligosaccharides and glycans. J. Anim. Sci. 2009, 87, 26-34. [CrossRef] [PubMed]

4. Shoaf-Sweeney, K.D.; Hutkins, R.W. Adherence, anti-adherence, and oligosaccharides preventing pathogens from sticking to the host. Adv. Food Nutr. Res. 2009, 55, 101-161. [PubMed] 
5. Smoot, J.T.; Demchenko, A.V. Oligosaccharide synthesis: From conventional methods to modern expeditious strategies. In Advances In Carbohydrate Chemistry And Biochemistry, 1st ed.; Horton, D., Ed.; Elsevier Inc.: Amsterdam, the Netherlands, 2009; Volume 62, pp. 161-250.

6. Zeuner, B.; Jers, C.; Mikkelsen, J.; Meyer, A. Methods for improving transglycosylation for synthesis of human milk oligosaccharide biomimetics. J. Agric. Food Chem. 2014, 62, 9615-9631. [CrossRef] [PubMed]

7. Zeuner, B.; Muschiol, J.; Holck, J.; Lezyk, M.; Gedde, M.R.; Jers, C.; Mikkelsen, J.D.; Meyer, A.S. Substrate specificity and transfucosylation activity of GH29 $\alpha$-L-fucosidases for enzymatic production of human milk oligosaccharides. New Biotechnol. 2018, 41, 34-45. [CrossRef] [PubMed]

8. Miura, T.; Okamoto, K.; Yanase, H. Purification and characterization of extracellular 1,2-alpha-L-fucosidase from Bacillus cereus. J. Biosci. Bioeng. 2005, 99, 629-635. [CrossRef]

9. Liu, S.W.; Chen, C.S.; Chang, S.S.; Mong, K.K.; Lin, C.H.; Chang, C.W.; Tang, C.Y.; Li, Y.K. Identification of essential residues of human $\alpha$-L-fucosidase and tests of its mechanism. Biochemistry 2009, 48, 110-120. [CrossRef]

10. Berteau, O.; McCort, I.; Goasdoué, N.; Tissot, B.; Daniel, R. Characterization of a new $\alpha$-L-fucosidase isolated from the marine mollusk Pecten maximus that catalyzes the hydrolysis of $\alpha$-L-fucose from algal fucoidan (Ascophyllum nodosum). Glycobiology 2002, 12, 273-282. [CrossRef]

11. Ogata-Arakawa, M.; Muramatsu, T.; Kobata, A. $\alpha$-L-Fucosidases from almond emulsin: Characterization of the two enzymes with different specificities. Arch. Biochem. Biophys. 1977, 181, 353-358. [CrossRef]

12. Khunsook, S.; Bean, B.S.; McGowan, S.R.; Alhadeff, J.A. Purification and characterization of plasma membrane associated human sperm $\alpha$-L-fucosidase. Biol. Reprod. 2003, 68, 709-716. [CrossRef] [PubMed]

13. Escamilla-Lozano, Y.; García-Garibay, M.; López-Munguía-Canales, A.; Gómez-Ruiz, L.; Rodríguez-Serrano, G.; Cruz-Guerrero, A. Synthesis of $\alpha$-L-fucosidase in different strains of lactic acid bacteria. Rev. Mex. Ing. Quím. 2015, 14, 623-629.

14. Rodríguez-Díaz, J.; Monedero, V.; Yebra, M.J. Utilization of natural fucosylated oligosaccharides by three novel alpha-L-fucosidases from a probiotic Lactobacillus casei strain. Appl. Environ. Microbiol. 2011, 77, 703-705. [CrossRef]

15. Morita, H.; Toh, H.; Oshima, K.; Murakami, M.; Taylor, T.; Igimi, S.; Hattori, M. Complete genome sequence of the probiotic Lactobacillus rhamnosus ATCC 53103. J. Bacteriol. 2009, 191, 7630-7631. [CrossRef] [PubMed]

16. Rodríguez-Díaz, J.; Carbajo, R.J.; Pineda-Lucena, A.; Monedero, V.; Yebra, M.J. Synthesis of fucosyl-N-acetylglucosamine disaccharides by transfucosylation using $\alpha$-L-fucosidases from Lactobacillus casei. Appl. Environ. Microbiol. 2013, 79, 3847-3850. [CrossRef]

17. Sikkema, J.; de Bont, J.A.M.; Poolman, B. Mechanisms of membrane toxicity of hydrocarbons. Microbiol. Rev. 1995, 59, 201-222. [PubMed]

18. Katayama, T.; Sakuma, A.; Kimura, T.; Makimura, Y.; Hiratake, J.; Sakata, K.; Yamanoi, T.; Kumagai, H.; Yamamoto, K. Molecular cloning and characterization of Bifidobacterium bifidum 1, 2- $\alpha$-L-fucosidase (AfCA), a novel inverting glycosidase (Glycoside Hydrolase Family 95). J. Bacteriol. 2004, 186, 4885-4893. [CrossRef]

19. Dong, S.; Chang, Y.; Shen, J.; Xue, C.; Chen, F. Purification, expression and characterization of a novel $\alpha$-l-fucosidase from a marine bacteria Wenyingzhuangia fucanilytica. Protein Expr. Purif. 2017, 129, 9-17. [CrossRef]

20. Eneyskaya, E.V.; Kulminskaya, A.A.; Kalkkinen, N.; Nifantiev, N.E.; Arbatskii, N.P.; Saenko, A.I.; Chepurnaya, O.V.; Arutyunyan, A.V.; Shabalin, K.A.; Neustroev, K.N. An $\alpha$-L-fucosidase from Thermus sp. with unusually broad specificity. Glycoconjugate J. 2001, 18, 827-834. [CrossRef]

21. Benešova, E.; Lipovova, P.; Dvorakova, H.; Kralova, B. $\alpha$-L-Fucosidase from Paenibacillus thiaminolyticus: Its hydrolytic and transglycosylation abilities. Glycobiology 2013, 23, 1052-1065. [CrossRef]

22. Shvetsova, S.V.; Shabalin, K.A.; Bobrov, K.S.; Ivanen, D.R.; Ustyuzhanina, N.E.; Krylov, V.B.; Nifantiev, N.E.; Naryzhny, S.N.; Zgoda, V.G.; Eneyskaya, E.V.; et al. Characterization of a new $\alpha$-l-fucosidase isolated

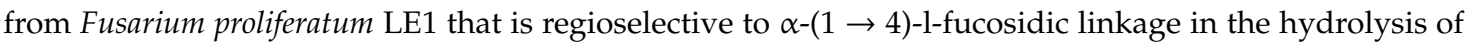
$\alpha$-l-fucobiosides. Biochimie 2017, 132, 54-65. [CrossRef]

23. Zeng, X.; Murata, T.; Usui, T. Glycosidase-catalyzed synthesis of fucosyl di- and trisaccharide derivatives using $\alpha$-L-fucosidase from Alcaligenes sp. J. Carbohydr. Chem. 2003, 22, 309-316. [CrossRef]

24. Ajisaka, K.; Shirakabe, M. Regioselective synthesis of $\alpha$-L-fucosyl-containing disaccharides by use of $\alpha$-L-fucosidases of various origins. Carbohydr. Res. 1992, 224, 291-299. [CrossRef] 
25. Farkas, E.; Thiem, J.; Ajisaka, K. Enzymatic synthesis of fucose-containing disaccharides employing the partially purified alpha-L-fucosidase from Penicillium multicolor. Carbohydr. Res. 2000, 328, 293-299. [CrossRef]

26. Guzmán-Rodríguez, F.; Alatorre-Santamaría, S.; Gómez-Ruiz, L.; Rodríguez-Serrano, G.; García-Garibay, M.; Cruz-Guerrero, A. Synthesis of a fucosylated trisaccharide via transglycosylation by $\alpha$-L-fucosidase from Thermotoga maritima. Appl. Biochem. Biotechnol. 2018, 186, 681-691. [CrossRef]

27. Petschacher, B.; Nidetzky, B. Biotechnological production of fucosylated human milk oligosaccharides: Prokaryotic fucosyltransferases and their use in biocatalytic cascades or whole cell conversion systems. J. Biotechnol. 2016, 235, 61-83. [CrossRef]

28. Reglero, A.; Cabezas, J. Glycosidases of molluscs. Eur. J. Biochem. 1976, 66, 379-387. [CrossRef]

29. Grove, D.S.; Serif, G. Porcine thyroid fucosidase. Biochim. Biophys. Acta 1981, 662, 246-255. [CrossRef]

30. Ruiz-Palacios, G.M.; Cervantes, L.E.; Ramos, P.; Chaves-Munguia, B.; Newburg, D.S. Campylobacter jejuni binds intestinal $\mathrm{H}(\mathrm{O})$ antigen (Fuc $\alpha 1,2 \mathrm{Gal} \beta 1,4 \mathrm{GlcNAc}$ ), and fucosyloligosaccharides of human milk inhibit its binding and infection. J. Biol. Chem. 2003, 278, 14112-14120. [CrossRef]

31. Weichert, S.; Jennewein, S.; Hufner, E.; Weiss, C.; Borkowski, J.; Putze, J.; Schroten, H. Bioengineered 2'-fucosyllactose and 3-fucosyllactose inhibit the adhesion of Pseudomonas aeruginosa and enteric pathogens to human intestinal and respiratory cell lines. Nutr. Res. 2013, 33, 831-838. [CrossRef]

32. Sotgiu, S.; Arru, G.; Fois, M.L.; Sanna, A.; Musumeci, M.; Rosati, G.; Musumeci, S. Immunomodulation of fucosyl-lactose and lacto- $\mathrm{N}$-fucopentaose on mononuclear cells from multiple sclerosis and healthy subjects. Int. J. Biomed. Sci. 2016, 2, 114-120.

33. Duska-McEwen, G.; Senft, A.P.; Ruetschilling, T.L.; Barrett, E.G.; Buck, R.H. Human milk oligosaccharides enhance innate immunity to respiratory syncytial virus and influenza in vitro. Food Nutr. Sci. 2014, 5, 1387-1398.

34. Cruz-Guerrero, A.; Hernández-Sánchez, H.; Figueroa-González, I. Commercial probiotic bacteria and prebiotic carbohydrates: A fundamental study on prebiotics uptake, antimicrobials production and inhibition of pathogens. J. Sci. Food Agric. 2014, 94, 2246-2252. [CrossRef]

Sample Availability: Samples of the compounds are available from the authors.

(C) 2019 by the authors. Licensee MDPI, Basel, Switzerland. This article is an open access article distributed under the terms and conditions of the Creative Commons Attribution (CC BY) license (http://creativecommons.org/licenses/by/4.0/). 